\title{
Memoria y autoficción en Todos éramos hijos, de María Rosa Lojo.
}

\author{
Josefina Ganuza ${ }^{1}$ \\ Universidad Nacional del Litoral - Facultad de Humanidades y Ciencias - CEC
}

Todos éramos hijos, de María Rosa Lojo. Buenos Aires: Sudamericana, 2014.

María Rosa Lojo anticipa, desde el proemio de su última novela Todos éramos hijos (2014), una modalización de lectura que no es menor: memoria antes que historia. Memoria viva y vigente de la vida de nuestra nación. El texto literario presenta las peculiaridades de la experiencia vivida, atravesada por el contexto, en el que el lector puede reconocer los espacios y las anécdotas que marcaron una época, influyente hasta nuestros días. Quizás sea apropiado destacar que el sentimiento de escritura se apropia de la experiencia para resemantizarla en el presente: «(...) si uno no está conforme, cambiar el presente, para saldar cuentas con el pasado. La mejor manera de saldar cuentas con el pasado es vivir un presente en el cual aquel pasado haya sido incorporado a nuestra propia experiencia» (Schmucler: 2007).

En lo autofictivo, Lojo recurre a su nombre propio en la construcción del personaje protagonista: Rosa, una adolescente hija de españoles inmigrantes (al igual que la misma autora), que irá conociendo y entendiendo el momento histórico en el que le toca crecer, y participa activamente del escenario pre-dictadura de la década del '70. La estrategia autofictiva le permite a la escritora apelar a la libertad de utilizar, en la ficción, elementos propios, sin apegarse de manera literaria y sin el contrato tradicional y discutido de veridicción de la autobiografía clásica. Es decir, la autoficción le posibilita la reconstrucción de época en primera persona, con reenvíos de verosímil, a efectos de

\footnotetext{
${ }^{1}$ Profesora en Letras (FHUC - UNL) y Especialista en Ciencias Sociales con mención en Lectura, Escritura y Educación (FLACSO), en Entornos Virtuales de Aprendizaje (OEI), en Educación y TIC (INFOD) y en Atención a la Diversidad (ISP 4987). Integrante del CEC. Próxima a completar la Licenciatura en Letras y la Maestría en Didácticas Específicas (FHUC - UNL), cursa el Doctorado en Humanidades en la misma institución. Ha integrado proyectos de investigación y publicado artículos con referato. Participa como expositora en encuentros científicos de su especialidad y se desempeña como docente titular en nivel secundario de educación pública de la Prov. de Santa Fe.
} 
resignificar el rol de la juventud y la iglesia católica, las instituciones (escuelas, universidades, etc.), familia y relaciones parentales, cuerpos sexuados, activismo de la mujer en el espacio público, por solo citar lo más representativo de la trama narrativa.

La novela se encuentra segmentada en actos, en claro diálogo intertextual con la obra de teatro de Arthur Miller Todos eran mis hijos: desde el título, la semiótica del hipotexto y el juego de fronteras entre géneros. Cada acto, a su vez, indica la unidad escénica de la trama narrativa, tal como en la dramaturgia, apostando a la construcción de un relato que, además, se propone representado y actualizado desde la lectura: sus personajes actúan, en la vida social, en los ámbitos institucionales en los que se proyectan, en la obra teatral de Miller que deberán actuar en la escuela, etc. El primer acto presenta a Frik (Rosa), y su ingreso a una escuela católica, regenteada por monjas. La filiación sinestésica, otra marca de agua Lojo, viaja en el tiempo desde el inicio para asegurar el anclaje de un pasado reciente pero fácilmente reconocible por los aromas, colores, sensaciones, enlazados en los espacios que se construyen:

Intentó concentrarse en la ceremonia inaugural, probando las primeras bocanadas de un aire que sólo se respiraba en la escuela y que la acompañaría -enriqueciéndose con olores acres y con nuevas suciedadesdurante los próximos once años. Un microclima hecho de polvo de tiza, cuero húmedo de zapatos, lana percudida por el sudor y salpicada por un vaho fugitivo de perfume empalagoso (Lojo, 2014:13).

Mencionamos la memoria como fundamento de lectura: la potencialidad del texto literario radica en recuperar la génesis de la juventud que comienza a ver «sin antifaz»: «Se terminó la forma en que nosotros y nuestros padres vivimos hasta ahora. Con tapones en los oídos, con antifaces protectores para dormir mejor (...)»(Lojo, 2014:62). La referencia del cronotopo enlaza el Concilio Vaticano II (1962-1965), el Consejo Episcopal Latinoamericano (CELAM, Medellín, 1968), y el surgimiento en nuestro país del Movimiento de Sacerdotes para el Tercer Mundo (MSTM), hacia una nueva mirada sobre la realidad del continente latinoamericano: deudores de la Revolución Cubana, pensar la militancia católica en servicio hacia la pobreza, y políticamente desde el peronismo. La lucha por la democracia y la libertad, contra la desigualdad de la oligarquía, en el seno mismo familiar que se divide gracias a estos pensamientos: «-¿Ah, sí? ¿Vos también? 
¿Usás cruz y poncho, como Esteban? ¿Vas a las villas a predicar el Evangelio peronista?» (Lojo, 2014: 94).

En suma, la propuesta literaria aborda reenvíos intertextuales, la estrategia autofictiva y la sinestesia, en un todo tendiente a actualizar la memoria colectiva, siempre presente e itinerante. En palabras de José Saramago, « (...) hay que recuperar, mantener y transmitir la memoria histórica, porque se empieza por el olvido y se termina en la indiferencia» (2005). Nunca más.

\section{Bibliografía}

Lejeune, P. (1994). El pacto autobiográfico (1973), pp.49-88

------ (1982) El pacto autobiográfico (bis)(pp.123-148). En El pacto autobiográfico y otros estudios. Madrid: Megazul-Endymion.

------ (1984) Autobiografía, novela y nombre propio (pp. 149-191). En El pacto autobiográfico y otros estudios. Madrid: Megazul-Endymion.

Lojo, M.R. (2014) Todos éramos hijos. Buenos Aires: Sudamericana. Saramago, J. (2005) De la sombra a la luz. Conferencia de la Jornada sobre la Recuperación de la Memoria Histórica en Jaén, España. Recuperado de http://elpais.com/tag/jose_saramago/a, consultado el 23/02/2014

Schmucler, H. (2007) Seminario 2006: Lo jóvenes y la transmisión de la experiencia argentina reciente. Ministerio de Educación de la Nación. Recuperado de educacionymemoria.educ.ar/...adernillo_secundario.pdf, consultado el 21/03/2017. 